\title{
Ekstraksi Ciri Sinyal EEG Untuk Gangguan Penyakit Epilepsi Menggunakan Metode Wavelet
}

\author{
Wiwit Putri Ani, Hindarto Hindarto
}

\begin{abstract}
Epilepsy occurs due to disorders of the nervous system of the human brain, recorded from the Elektroensephalogram signal (EEG). EEG signal contains information of electrical activity in the brain, including the condition of electrical interference on the mind and nerves. EEG signal has a complex shape, amplitude is small, easily buried by noise and has no raw, so the pattern analysis visually isn't easy [1] to increase accuracy and eliminate noise from EEG signals, this research method using Wavelet as the extraction process for classification and characteristics of Backpropagation. EEG signals data at the University of Bonn consists of five classes of datasets, namely A, B, C, D, and e. Each dataset contains 100 single channel EEG segments with duration over 23.6 seconds. Researchers use dataset B and e. On stage training (training) uses 80 naracoba, whereas at this stage of testing (testing) use 100 naracoba. This process is done after extracting the characteristics of EEG signals with Wavelet. The results of the extraction of the characteristics used in the value of the input, on the research method using back propagation (16-35-2) i.e. EEG signal input 2, one hidden layer with the 35 units and two target epilepsy and non epileptic. the data obtained from testing of the accuracy value of $100 \%$.
\end{abstract}

Keywords: Backpropagation, Wavelet, epilepsy, EEG

Abstrak- Epilepsy terjadi karena ada gangguan sistem saraf otak pada manusia, yang terekam dari sinyal Elektroensephalogram. Sinyal Elektroensephalogram memiliki informasi aktivitas listrik pada otak, termasuk kondisi gangguan kelistrikan dan pikiran pada syaraf. Sinyal Elektroensephalogram mempiliki bentuk yang kompleks, mudah tertimbun noise, amplitudo kecil dan tidak memiliki pola yang baku, sehingga analisa secara visual tidak mudah ${ }^{[1]}$ Untuk meningkatkan akurasi dan menghilangkan noise dari sinyal EEG, penelitian ini menggunakan metode Wavelet sebagai proses ekstraksi ciri dan Backpropagation untuk klasifikasi. Data sinyal Elektroensephalogram didapat dari Universitas Bonn yang terdiri dari 5 kelas dataset yaitu A, B, C, D, dan E. Tiap dataset berisi 100 segmen EEG saluran tunggal dengan durasi selama 23.6 detik. Peneliti menggunakan dataset B dan E. Pada tahap pelatihan (training) menggunakan 80 naracoba , sedangkan pada tahap pengujian (testing) menggunakan 100 naracoba. Proses ini dilakukan setelah ekstraksi ciri sinyal EEG dengan Wavelet. Hasil ekstraksi ciri digunakan sabagai nilai input, pada penelitian ini menggunakan metode back propagation (16-35-2) yaitu 2 input sinyal EEG, satu hidden layer dengan 35 unit dan dua target epilepsy dan non epilepsi . dari pengujian data tersebut didapat nilai akurasi sebesar $100 \%$.

Kata kunci : Backpropagation, Wavelet, epilepsy, EEG

\section{PENDAHULUAN}

E pilepsi terjadi karena ada gangguan sistem syaraf otak pada manusia, yang terekam dari sinyal Elektroensephalogram. Sinyal EEG mengandung informasi aktivitas listrik di otak manusia, termasuk kondisi pikiran dan gangguan kelistrikan yang terdapat di syaraf. Sinyal EEG mempunyai bentuk yang kompleks, sehingga analisis secara visual tidak mudah. Elektroensefalografi (EEG) adalah metode penyelidikan yang memberikan informasi untuk klasifikasi, diagnosis, dan terapi kondisi otak. Frekuensi dan isi energi dari sinyal EEG dapat mengandung informasi yang berguna mengenai sifat penyakir yang mempengaruhi otak. Pada masa lalu, para dokter diminta untuk melakukan analisis EEG visual. Untuk mengurangi beban kerja, maka dikembangkanlah program komputer untuk analisis biosinyal. Sejak pertama kali diperkenalkannya program yang tersedia secara komersial, sistem analisis EEG terkomputerisasi telah menjadi semakin canggih dan murah dengan semakin bertambahnya jumlah program yang tersedia. Penggunaan analisis EEG terkomputerisasi telah dengan cepat meningkatkan pelayanan kesehatan. Informasi yang diperoleh melalui analisis terkomputerisasi ini digunakan untuk mendeteksi dan mendiagnosis aktivitas otak yang normal dan abnormal $^{[2]}$ Penelitian ini dilakukan untuk memotong sinyal menjadi beberapa bagian, kemudian menganalisa bagian-bagian tersebut secara terpisah. Dengan menganalisa sebuah sinyal seperti ini akan memberikan informasi tentang kapan dan dimana komponen perbedaan frekuensi. Dan untuk menyelesaikan masalah ini digunakan metode wavelet. Definisi dari wavelet 
adalah bentuk gelombang .small wave. dengan energi yang terkonsentrasi pada suatu waktu tertentu. Selain berosilasi sebagaimana gelombang, wavelet juga memiliki kemampuan untuk menganalisis waktu dan frekuensi secara simultan, sehingga wavelet dapat digunakan sebagai tool untuk menganalisis fenomena yang bersifat transien, non stasioner, atau berubah terhadap waktu.. Salah satu contoh penelitian yang berhubungan dengan penelitian ini adalah "Denoising \& Feature Extraction Of EEG Signal Using Wavelet Transform" yang ditulis oleh Sachin Garg 1, Rakesh Narvey pada tahun 2013 , Jurnal ini mengusulkan suatu teknik mendeteksi gangguan epilepsi menggunakan diskrit wavelet mengubah menggunakan MATLAB.

Kelebihan wavelets sebagai fungsi transform adalah adanya fungsi kompresi (dilation) dan pergeseran (translation) dalam fungsi induknya. Fungsi basis yang pertama direkonstruksi adalah derivative kedua dari fungsi Gaussian, karena bentuknya yang ber-ombak (wavy) maka penemu dari metode tersebut menamakannya dengan sebutan wavelets

\section{METODOLOGI PENELITIAN}

Penelitian yang akan dilakukan meliputi beberapa langkah : Pengambilan data sinyal EEG, Normalisasi sinyal EEG, penggunakan fungsi Wavelet Transform, serta pengenalan Sinyal EEG menggunakan Jaringan Syaraf Tiruan BackPropagation.

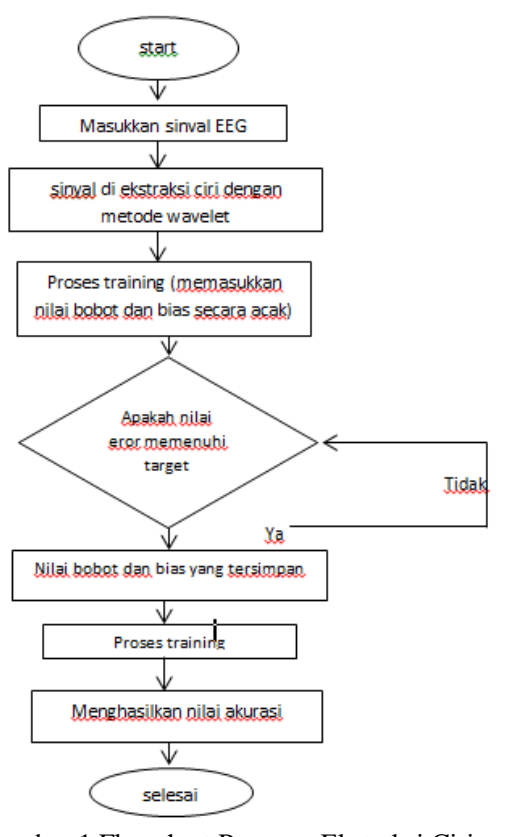

Gambar 1.Flowchart Program Ekstraksi Ciri

\section{III.EKSTRAKSI CIRI DENGAN METODE WAVELET}

Implementasi transformasi wavelet diskrit dapat dilakukan dengan cara melewatkan sinyal frekuensi tinggi atau highpass filter dan frekuensi rendah atau lowpass filter. Ekstraksi ciri sinyal EEG diperoleh dengan cara mendekomposisi sinyal tersebut hingga 4 tingkat menggunakan transformasi wavelet. Ilustrasi dekomposisi sinyal EEG 4 seperti gambar 2 Tiap sinyal EEG didekomposisi hingga 4 tingkat.

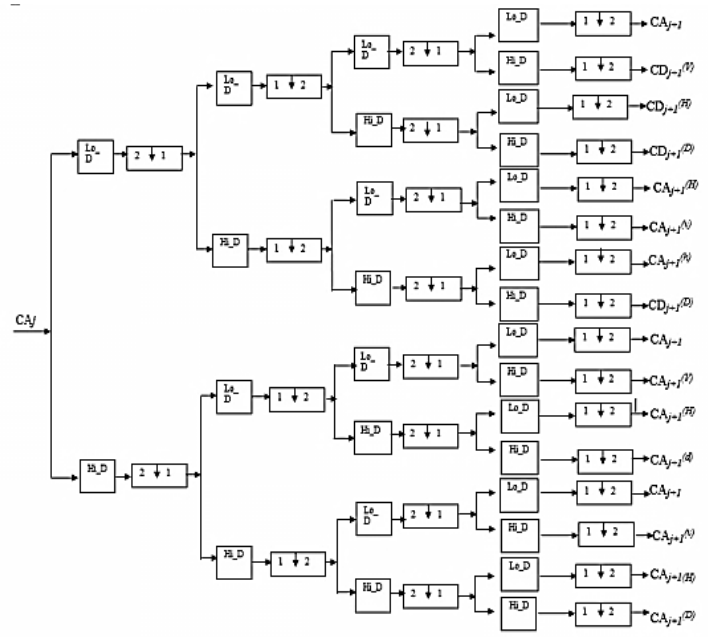

Gambar 2. Esktraksi ciri dengan Metode wavelet

\section{KLASIFIKASI DENGAN JARINGAN SYARAF BACKPROPAGATION}

Pada proses klasifikasi, identifikasi sinyal EEG diproses menggunakan back propagation. Backpropagation adalah bentuk jaringan syaraf tiruan yang terdiri dari beberapa layer. Jaringan syaraf tiruan backpropagation melatih jaringan untuk mendapatkan keseimbangan antara kemampuan jaringan untuk mengenali pola yang digunakan selama pelatihan serta kemampuan jaringan untuk memberikan respon yang benar terhadap pola masukan yang serupa (tapi tidak sama) dengan pola yang dipakai selama pelatihan. ${ }^{[4]}$ seperti ditunjukkan pada gambar 3 Proses ini dilakukan setelah ekstraksi ciri sinyal EEG dengan Wavelet Diskrit. Hasil ekstraksi ciri digunakan sabagai nilai input, pada penelitian ini menggunakan metode back propagation (16-35-2) yaitu 16 input sinyal EEG, satu hidden layer dengan 35 unit dan satu target (Epilepsi dan Non Epilepsi).

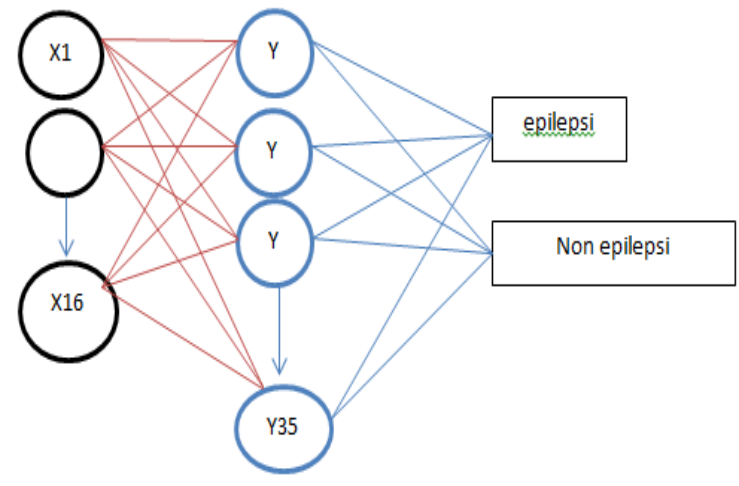

Gambar 3. Arsitektur jaringan Back Propagation Satu Hidden Layer

Proses klasifikasi terdiri dari dua tahap, pertama proses pembelajaran atau training. Kedua proses mapping atau proses pengujian/testing. Proses training yaitu dengan mencari nilai bobot terbaik dengan perolehan nilai error terkecil dari target keluaran yang diinginkan. Pada algoritma backpropagation untuk mengubah nilai bobot menggunakan error output dengan arah mundur (backward). Sebelumnya harus melakukan tahap perambatan maju (fordward) untuk mendapatkan nilai 
error, neuron - neuron akan diaktifkan dengan menggunakan fungsi aktivasi sigmaoid. Apabila keluaran backword pada lapisan tersembunyi (hidden layer) tidak sama dengan keluaran yang diinginkan, maka akan diteruskan kedalam lapisan masukan (input layer). Pada algoritma backpropagation nilai error dapat diminimalkan dengan menggunakan persamaan berikut :

$$
M S E=\frac{1}{2} \sum_{i=1}^{n}\left(d_{l k}-O_{l k}\right)^{2}
$$

Dengan:

$$
\begin{aligned}
& \mathrm{n}=\text { jumlah dari sample data } \\
& \mathrm{dlk}=\text { nilai output yang ditargetkan } \\
& \mathrm{Olk}=\text { nilai output keluaran aktual }
\end{aligned}
$$

\section{HASIL DAN PEMBAHASAN}

Hasil dari penelitian ini berupa sebuah perangkat lunak untuk mengekstraksi ciri dari sinyal EEG untuk gangguan penyakit epilepsy menggunakan metode wavelet sebagai ekstraksi ciri dan mengaplikasikan backpropagation untuk klasifikasi.

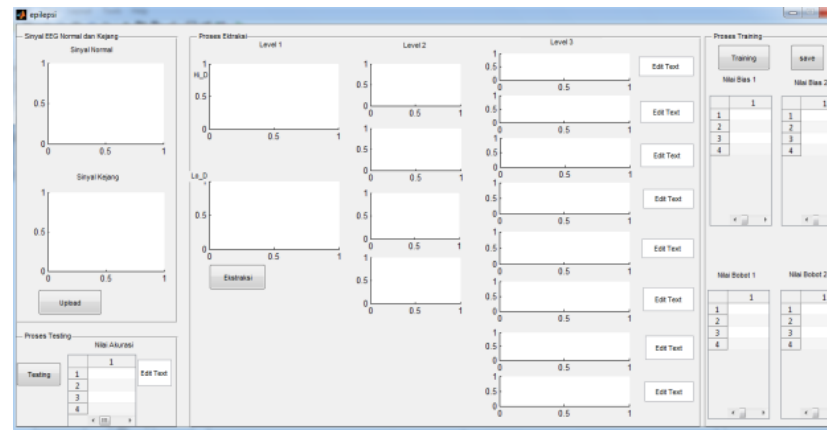

Gambar 4. Gambar Halaman Utama dari Program

Gambar 4. adalah berupa halaman utama pada program yang berisi beberapa tombol untuk melakukan proses, axes untuk menampilkan sinyal EEG sebelum dan sesudah diekstaksi, table untuk menampilkan data dan edit untuk menampilkan data. tombol upload digunakan untuk melakukan proses menampilkan sinyal EEG, tombol ekstraksi untuk melakukan proses ekstraksi sinyal EEG,tombol training untuk melakukan proses training, dan tombol testing untuk melakukan proses testing.

1. Tombol Upload

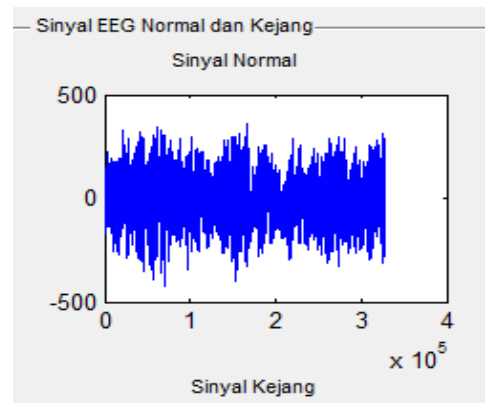

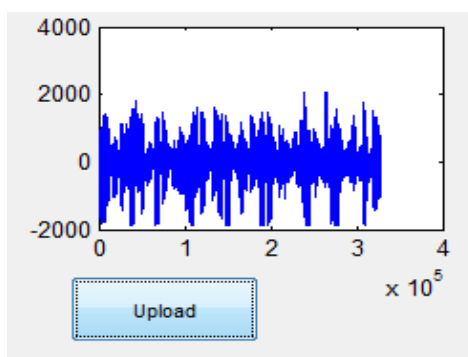

Gambar 5. Gambar Tampilan dari Tombol Upload

Gambar 5.adalah tampilan dari hasil proses tombol upload yang berfungsi untuk melakukan upload atau menampilkan sinyal EEG kedalam program.

\section{Tombol Ekstraksi}

Gambar 6. adalah gambar dari fungsi tombol ekstraksi yang berfungsi untuk melakukan proses dan menampilkan hasil ekstraksi. Pertama sinyal EEG yang sudah di upload akan dibagi menjadi tiga level.

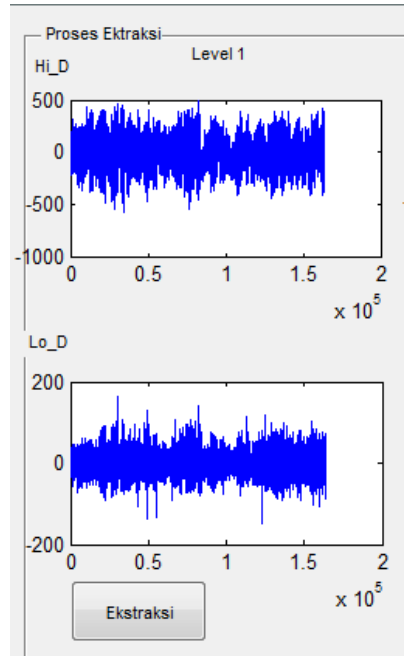

Gambar 6. Gambar Push Button Ekstraksi.

\section{Tombol Training}

Pada push button training digunakan untuk melakukan proses backpropagation tahap training (pelatihan). Pada tahap ini inputan yang didapat dari proses ekstraksi akan dilatih untuk mendapatkan nilai error sesuai target dan mendapatkan nilai bias dan bobot yang tepat sehingga dan kemudian nilai bias dan bobot tersebut disimpan yang nantinya akan digunakan pada tahap testing (pengujian). Jika push button ekstraksi dijalankan maka akan muncul tampilan proses tahap backpropagatin seperti terlihat pada gambar 7 . 


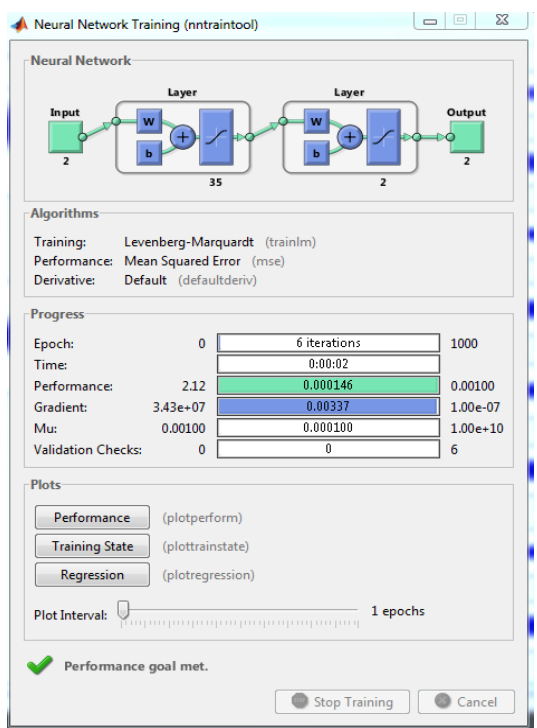

Gambar 7. Proses Training Backpropagation

Pada gambar 7. ditunjukkan bahwa target error (mse) tercapai pada epoch ke-6. Setelah proses backpro selesai maka akan muncul tampilan seperti gambar 8 yang merupakan hasil nilai bias dan bobot yang paling tepat. Kemudian program akan menyimpan nilai bias dan bobot tersebut.
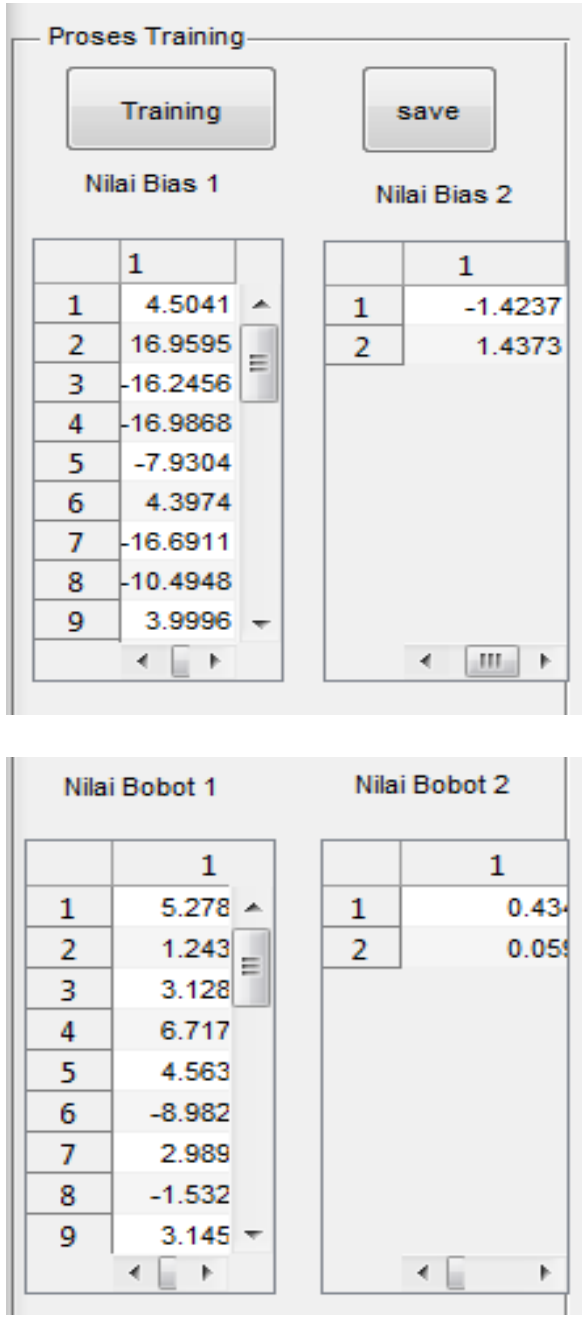

\section{Tombol Testing}

Pada push button testing digunakan untuk melakukan proses backpropagation tahap testing (pengujian). Pada tahap ini backpo akan melakukan pengkelasan dengan menggunakan nilai bias dan bobot dari tahap training yang sudah tersimpan. Pertama sebelum melakukan proses training, terlebih dahulu untuk mengupload sinyal EEG untuk testing dengan jumlah data yang lebih banyak dari data yang digunakan untuk tahap training yaitu 80 data. Setelah itu dilakukan proses ekstraksi lagi untuk menemukan nilai ekstraksi ciri dari sinyal EEG yang baru ter-upload. Baru kemudian dilakukan proses testing dan program akan menampilkan hasil output nilai backpro dari tahap testing dan nilai akurasinya seperti pada gambar 9 .

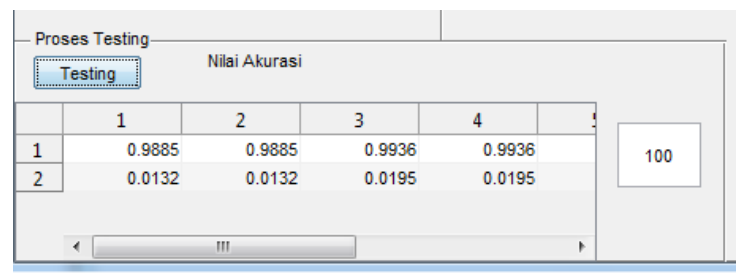

Gambar 9. Nilai Keluaran Tahap Testing dan Nilai Akurasinya

Dari gambar 9 menunjukkan nilai akurasi mencapai $100 \%$ yang berarti nilai keluaran aktual sesuai dengan nilai keluaran yang ditargetkan.

\section{HASIL PENGUJIAN}

Dalam penelitian ini lebih menekankan pada identifikasi sinyal EEG dengan menganalisis sinyal EEG menggunakan metode wavelet, selanjutnya hasil ekstraksi fitur akan masuk ke proses pembejaran dan pengujian menggunakan jaringan syaraf tiruan back propagation.

Untuk proses ektraksi sinyal EEG akan dipilah - pilah menurut kelasnya, yaitu epilepsy dan non epilepsy . Data ini akan menjadi ciri dari sinyal EEG. Tabel 1. adalah hasil ekstraksi ciri sinyal EEG. Data hasil ekstraksi ciri ini akan mejadi nilai input untuk proses pembelajaran (training) klasifikasi menggunakan metode back propagation. nilai akurasi mencapai $100 \%$ yang berarti nilai keluaran aktual sesuai dengan nilai keluaran yang ditargetkan. Dimana nilai keluaran yang ditagetkan yaitu 1 dan 0, dapat ditunjukkan pada gambar 9 baris pertama keluaran aktual menunnjuakkan nilai 0,9885 - 1 membuktikan nilai keluaran aktual sesuai dengan nilai keluaran target 1 . Sedangkan pada gambar 9 baris kedua nilai keluaran aktual menunjukkan nilai 0.0132 - 0 yang membuktikan nilai keluaran aktual sesuai dengan nilai keluaran yang ditargetkan yaitu 0. Dengan demikian metode backpropagation (16-35-2) dapat melakukan klasifikasi dengan tepat. Sebelumnya sudah dilakukan beberapa percobaan untuk menemukan metode backpropagation yang tepat. Pertama menggunakan metode backpropagation (16-80-2) nilai akurasi $87.5 \%$, kedua menggunakan metode backpropagation (16-77-2) nilai akurasi hanya mencapai $81.25 \%$. 


\section{KESIMPULAN}

Dari hasil penelitian pada bab yang sudah dibahas sebelumnya dapat diambil kesimpulan bahwa :

Pada penelitian ini peneliti menggunakan metode Wavelet dan Backpropagation sebagai klasifikasinya.. Pada tahap pelatihan (training) menggunakan 80 naracoba, sedangkan pada tahap pengujian (testing) menggunakan 100 naracoba.

Penelitian ini menggunakan metode back- propagation (16-35-2) yaitu 2 input sinyal EEG, satu hidden layer dengan 35 unit dan dua target epilepsy dan non epilepsi . dari pengujian data tersebut didapat nilai akurasi sebesar $100 \%$.

\section{DAFTAR PUSTAKA}

[1] Zulianto .W.E dkk.(2016) "Deteksi Epilepsi Dari Sinyal Eeg Menggunakan Autoregressive

Dan Adaptive Backpropagation”. (120-125)

[2] Ferara, L. (2014)." Klasifikasi Epilepsi Dalam Sinyal Eeg Dengan Metode Hilbert

Huang Transform" (1-9)

[3] Hindarto." Klasifikasi Sinyal Elektrode Enchepalo Graph (Eeg)

Menggunakan Metode Wavelet” (5,11-18)

[4] Sulistiyasni, Winarko, E.(2014)" Klasifikasi Pola Sidik Jari Menggunakan Jaringan Syaraf Tiruan Backpropagation

Classification of Fingerprint Pattern Using Backpropagation Neural Network "(215 